\title{
Outcome of Neonatal Hyperbilirubinemia from a Tertiary Care Hospital in Eastern Nepal: A Cross-sectional Study
}

\author{
- Shyam Prasad Kafle ${ }^{1} \bullet$ Mukesh Bhatta ${ }^{1} \bullet$ Ramesh Shrestha $^{2} \bullet$ Sarita Situala $^{2} \bullet$ Namu Koirala $^{3}$ \\ - Anupam Koirala ${ }^{4}$
}

Submitted 13 December 2020

” Shyam Prasad Kafle kafle.shyam11@gmail.com

(iD https://orcid.org/0000-0001-6332-9880

${ }^{1}$ Department of Pediatrics and Adolescent Medicine, BPKIHS, Nepal

2 Department of Obstetrics and Gynecology, BPKIHS, Nepal

${ }^{3}$ Department of Nursing, Purbanchal University School of Health Sciences, Gothgaon, Nepal

${ }^{4}$ Letang Primary Health Care Center, Letang, Nepal

\section{Citation}

“Kafle SP, Bhatta M, Shrestha R, Sitaula $S$, Koirala $N$, Koirala A. Outcome of neonatal hyperbilirubinemia from a tertiary care hospital in eastern Nepal: A cross-sectional study. JBPKIHS. 2021;4(1):37-42.

doi https://doi.org/10.3126/jbpkihs.v4i1.36324

\section{(c) (i) $\odot$}

This work is licensed under a Creative Commons Attribution NonCommercial 4.0 International License.
Accepted 12 March 2021

Published 30 June 2021

Background: Timely detection and treatment of pathological hyperbilirubinemia in newborns can prevent acute bilirubin encephalopathy and its consequences. We aimed to identify its occurrence, presentation time, phototherapy duration, need for exchange transfusion, and outcome.

Methods: In this cross-sectional study, we enrolled all the babies admitted for pathological neonatal hyperbilirubinemia in the university hospital of BPKIHS in a one-year duration. Babies with life-threatening congenital malformations or conjugated bilirubin $>20 \%$ of total serum bilirubin or $>2 \mathrm{mg} / \mathrm{dl}$ were excluded. Obstetric profile of mothers, clinical and laboratory parameters of babies, onset time of pathological jaundice, duration of phototherapy, need for exchange transfusion or intravenous immunoglobulin were recorded. Neonatal outcome was classified as good and poor and its association with potential predictors analyzed.

Results: One-hundred and fifty babies developed neonatal jaundice requiring treatment. The most common causes included $A B O$ and Rh setting. No cause was found in 26 (18\%) babies. One-hundred and eight babies (72\%) were only managed with phototherapy whereas $42(28 \%)$ required both phototherapy and double volume exchange therapy. The majority (84.5\%) had good outcome without any residual neurological deficit at discharge. Babies with total serum bilirubin $>20 \mathrm{mg} / \mathrm{dl}$ at presentation, duration of phototherapy $>44.8 \mathrm{~h}, \mathrm{ABO}$ setting, hemolysis, and out born status significantly developed poor outcome $(\mathrm{p}<0.05)$.

Conclusion: About 15\% of the babies with hyperbilirubinemia had acute bilirubin encephalopathy at discharge suggestive of poor outcome. Babies with high bilirubin at presentation, longer duration of phototherapy, $A B O$ settings, hemolysis, and out born status developed poor outcome.

Keywords: Bilirubin, Hyperbilirubinemia, Nepal, Newborn

\section{Declarations}

Ethics approval and consent to participate: Ethical approval obtained from the Institutional Review Committee, B. P. Koirala Institute of Health Sciences (Ref. No. Acd/ 378/ 077/ 078). Informed consent was taken from the parents before enrollment in the study.

Consent for publication: Not applicable

Availability of data and materials: The datasets used and/ or analyzed during the current study are available from the corresponding author on reasonable request. All relevant data are within the manuscript.

Competing interest: None

Funding: None

Authors' contributions: SPK: concept, design, intellectual content, literature search, data acquision, and analysis. MB: design, literature search, and data acquision. RS: design, literature search, and data acquision. SS: design, literature search, and data acquision. NK: concept, design, intellectual content, literature search, and analysis. AK: design, and literature search. All the authors have read and approved the final manuscript.

Acknowledgement:We would like to acknowledge the HOD, Department of Paediatrics and Adolescent Medicine, and Professor Nisha Keshari Bhatta, Chief, Division of Neonatology, BPKIHS, Dharan for their support and guidance for conducting this study. We would also like to thank all the study participants for participating in this study and their parents, without whom this study would have been impossible. 
$\mathrm{N}$ eonatal jaundice is reported in $>50 \%$ of newborns $[1,2]$. The most common form of neonatal jaundice is physiological but sometimes serum bilirubin levels exceed the normal range to become pathological $[3,4]$. Timely detection of pathological hyperbilirubinemia and prompt treatment can prevent severe consequences like bilirubin encephalopathy. Apart from phototherapy, severe hyperbilirubinemia is managed with exchange transfusion which may be associated with complications. With the advent of newer phototherapy techniques, better understanding of pathophysiology, underlying causes, and interventions, the need for exchange transfusion is decreasing. We conducted this study to analyze the average time of presentation, possible causes, mean duration of phototherapy, need for exchange transfusion and discharge outcome of pathological jaundice in newborns.

\section{METHODS}

$\mathrm{T}$ his cross-sectional study was conducted in B. P. Koirala Institute of Health Sciences (BPKIHS), Dharan from August 2015 to July 2016. Ethical clearance was taken from the Institutional Review Committee and informed consent was taken from the parents before enrollment in the study. All the babies admitted in the neonatal ward, nursery, neonatal intensive care unit (NICU) and pediatric wards diagnosed with neonatal hyperbilirubinemia requiring treatment were enrolled. Babies with life-threatening congenital malformations or those having conjugated serum bilirubin $>20 \%$ of total serum bilirubin or $>2 \mathrm{mg} / \mathrm{dl}$ were excluded.

Serum bilirubin was measured by Jendrassik and Grof method by a fully automated analyzer [5]. A predesigned proforma was filled from the case files; details such as demographic and obstetric profile of the mother, physical examination of the baby, time since birth to the appearance of pathological jaundice, other relevant blood investigations, duration of phototherapy, need for exchange transfusion, intravenous immunoglobulin, and intravenous fluid requirement were recorded sequentially and serially. Babies were classified into term, preterm, late preterm, appropriate for gestational age, low birth weight, small for gestational age as per the standard definitions [6].

All babies who had neither Rh nor ABO setting were checked for deficiency of glucose-6-phosphate dehydrogenase (G6PD) if there was evidence of hemolysis in the peripheral smear. A final assessment was done after obtaining all the clinical and laboratory information for identifying the possible cause of jaundice.

All the babies were followed up till discharge from the hospital. All phototherapy units were of the same quality and adjusted similarly for distance and wavelength (Lullaby [GE], Zeal medical; 420-470 nm wavelength). Management of pathological hyperbilirubinemia or diagnosis of acute bilirubin encephalopathy was based on the American Academy of Pediatrics guidelines [4]. The outcome was mentioned at the time of discharge as good and poor based on the presence of residual neurological deficit at discharge. Statistical analysis was performed in Statistical Packages for Social Science version 11 (SPSS Inc; Chicago, IL, USA). Predictors for the poor outcome were assessed by the Pearson's chi-square test, Fisher Exact test, and Student's t-test. The data were presented as number of patients, percentage, mean, and standard deviation.

\section{RESULTS}

uring the study period, 150 newborns with hyperbilirubinemia had fulfilled the inclusion criteria. There was no missing data. Maternal age (mean \pm SD) was 24.9 \pm 3.4 years. Most mothers were primigravida, Hindu by religion, and from the hilly region. Nearly four-fifth (79.3\%) of babies were born through spontaneous vaginal delivery, followed by cesarean section (12\%) and assisted vaginal delivery (8.7\%). More than two-third (68\%) of the newborns were term and the majority (66\%) presented to the hospital at 4th to 7 th day of life (Table 1).

The hemoglobin level (mean \pm SD) of the neonates was $14.69 \pm 2.28 \mathrm{gm} / \mathrm{dl}$. The total serum bilirubin level (mean $\pm \mathrm{SD}$ ) at presentation was $21.73 \pm 5.15$ $\mathrm{mg} / \mathrm{dl}$ and the majority (44.7\%) had bilirubin level $<20$ $\mathrm{mg} / \mathrm{dl}$ (Table 2). Fifty-five babies (37\%) had ABO blood group mismatch with their respective mothers whereas 11 (7.3\%) had Rh setting. In 6 (4\%) babies, peripheral smear was suggestive of hemolysis without $\mathrm{ABO} / \mathrm{Rh}$ setting. Sepsis was found in $52(34.6 \%)$ babies. The remaining 26 (17.4\%) babies had no identifiable cause of jaundice.

More than two-third (72\%) received only phototherapy and the majority (50\%) received it for 24 to 48 $h$. The duration of phototherapy (mean \pm SD) was 47.34 $\pm 16.68 \mathrm{~h}$. Six babies who had incompatibility suggestive of hemolysis received all forms of therapy including phototherapy, exchange transfusion, and IV immunoglobulin as their total bilirubin level was above the ex- 
Table 1: Baseline characteristics of mothers $(n=150)$ and neonates $(n=150)$. Values are expressed as number (\%).

\begin{tabular}{|c|c|c|}
\hline \multicolumn{2}{|c|}{ Baseline characteristics } & Frequency $\mathrm{n}(\%)$ \\
\hline \multicolumn{3}{|l|}{ Mothers } \\
\hline \multirow[t]{3}{*}{ Age $(y)$} & $17-19$ & $8(5.3)$ \\
\hline & $20-34$ & $|4|(94.0)$ \\
\hline & $>34$ & I (0.7) \\
\hline \multirow[t]{4}{*}{ Religion } & Hindu & $105(70.0)$ \\
\hline & Kirat & $29(19.3)$ \\
\hline & Muslim & $5(3.3)$ \\
\hline & Others & II (7.3) \\
\hline \multirow[t]{2}{*}{ Gravida } & Primigravida & $86(57.3)$ \\
\hline & Multigravida & $64(42.7)$ \\
\hline \multirow[t]{2}{*}{ Place of delivery } & Inborn & $82(54.7)$ \\
\hline & Out born & $68(45.3)$ \\
\hline \multirow[t]{2}{*}{ Residence } & Hill & $77(5 \mid .3)$ \\
\hline & Terai & $73(48.7)$ \\
\hline \multirow[t]{3}{*}{ Mode of delivery } & SVD & $119(79.3)$ \\
\hline & Assisted & $13(8.7)$ \\
\hline & LSCS & $18(12.0)$ \\
\hline \multicolumn{3}{|l|}{ Neonates } \\
\hline \multirow{4}{*}{$\begin{array}{l}\text { Gestational age at } \\
\text { birth }\end{array}$} & Preterm & $22(14.7)$ \\
\hline & Late preterm & $26(17.3)$ \\
\hline & LBW & $57(38.0)$ \\
\hline & Normal & $86(57.3)$ \\
\hline \multirow[t]{2}{*}{ Size at birth } & SGA & $34(22.7)$ \\
\hline & AGA & 116 (77.3) \\
\hline \multirow[t]{2}{*}{ Gender } & Male & $78(52.0)$ \\
\hline & Female & $72(48.0)$ \\
\hline \multirow[t]{3}{*}{ Age at presentation } & $<72 \mathrm{~h}$ & $36(24.0)$ \\
\hline & 72 h - 7 days & $99(66.0)$ \\
\hline & $>7$ days & $15(10.0)$ \\
\hline
\end{tabular}

SVD: Spontaneous vaginal delivery; LSCS: Lower segment Cesarean section; LBW: low birth weight; SGA: small for gestational age;AGA: appropriate for gestational age.

change range at the time of presentation. The majority (84.5\%) had good outcome with complete recovery at discharge. Twenty-three babies had poor outcome with residual neurological deficit at discharge suggestive of acute bilirubin encephalopathy (Table 3).

Among the attributable risk factors assessed, $\mathrm{ABO}$ setting, hemolysis, out born babies, total serum bilirubin (TSB) level above $20 \mathrm{mg} / \mathrm{dl}$ at presentation and the duration of phototherapy more than $44.8 \mathrm{~h}$ predicted poor outcome (Table 4, 5).
Table 2: Laboratory and clinical findings at admission ( $n$ $=150$ ). Values are expressed as number (\%)

\begin{tabular}{lll}
\hline Parameters & Values & Frequency $\mathrm{n}(\%)$ \\
\hline $\mathrm{Hb}(\mathrm{gm} / \mathrm{dl})$ & $<13$ & $47(3 \mathrm{I} .3)$ \\
& 14 to 20 & $10 \mathrm{I}(63.3)$ \\
& $>20$ & $2(1.4)$ \\
$\mathrm{TSB}(\mathrm{mg} / \mathrm{dl})$ & $<20$ & $68(44.7)$ \\
& 20 to 25 & $54(37)$. \\
& 25 to 30 & $17(\mathrm{II})$. \\
& $>30$ & $11(7.3)$ \\
ABO setting & Yes & $55(36.7)$ \\
& No & $95(63.3)$ \\
Rh setting & Yes & $11(7.3)$ \\
& No & $139(92.7)$ \\
Hemolysis & Yes & $6(4.0)$ \\
Sepsis & No & $144(4.0)$ \\
& Yes & $52(34.6)$ \\
& No & $98(65.4)$ \\
\hline
\end{tabular}

Hb: hemoglobin;TSB: total serum bilirubin

Table 3: Details of treatment received and the immediate outcome $(n=150)$. Values are expressed as number $(\%)$.

\begin{tabular}{|c|c|c|}
\hline Parameters & & Frequency $\mathrm{n}(\%)$ \\
\hline \multirow{3}{*}{$\begin{array}{l}\text { Treatment } \\
\text { received }\end{array}$} & Phototherapy only & $108(72.0)$ \\
\hline & $\begin{array}{l}\text { Both phototherapy and ex- } \\
\text { change transfusion }\end{array}$ & $36(24.0)$ \\
\hline & $\begin{array}{l}\text { Phototherapy, exchange trans- } \\
\text { fusion and IV Ig }\end{array}$ & $6(4.0)$ \\
\hline \multirow{4}{*}{$\begin{array}{l}\text { Duration of } \\
\text { phototherapy } \\
\text { (h) }\end{array}$} & $<24$ & $8(5.3)$ \\
\hline & 24 to 48 & $75(50.0)$ \\
\hline & 48 to 72 & $56(37.4)$ \\
\hline & $>72$ & II (7.3) \\
\hline \multirow[t]{2}{*}{ Outcome } & Good & $127(84.7)$ \\
\hline & Poor & $23(15.3)$ \\
\hline
\end{tabular}

IV Ig: intravenous immunoglobulin

\section{DISCUSSION}

This study describes the demographic characteristics of both mothers and new-borns with hyperbilirubinemia, clinical findings at admission, biochemical parameters, risk factors associated with neonatal hyperbilirubinemia, duration of phototherapy, and immediate outcome.

ABO setting was noted in $36.7 \%$ of babies whereas $\mathrm{Rh}$ setting was noted in $7.3 \%$ of the babies. ABO setting has been reported as the most common cause accounting for $13.5 \%$ to $27 \%$ of the babies with hyperbilirubinemia $[1,7,8]$. None of our babies were found to 


\begin{tabular}{|c|c|c|c|c|}
\hline Risk factors & & Good outcome $(n=\mid 27)$ & Poor outcome $(n=23)$ & $p$-value \\
\hline Prematurity & Present/ absent & $34 / 93$ & $4 / 19$ & $0.31^{*}$ \\
\hline Septicemia & Present/ absent & $42 / 85$ & $|2 / 1|$ & $0.54^{\#}$ \\
\hline$A B O$ setting & Present/ absent & $43 / 84$ & $|2 / 1|$ & $0.03^{\#}$ \\
\hline Rh setting & Present/ absent & $9 / 118$ & $2 / 21$ & $0.35^{*}$ \\
\hline G6PD deficiency & Present/ absent & $0 / 127$ & $1 / 22$ & $0.15^{*}$ \\
\hline Place of delivery & Inborn / out born & $75 / 52$ & $7 / 16$ & $0.0 I^{\#}$ \\
\hline Hemolysis & Present/ absent & $1 / 126$ & $5 / 18$ & $<0.001^{\prime}$ \\
\hline
\end{tabular}

*Fisher Exact test, \#Pearson's Chi-Square test. G6PD: Glucose-6-phosphate dehydrogenase.

Table 5: Comparison of various parameters with outcome $(n=150)$. Values are expressed as mean \pm SD.

\begin{tabular}{llll}
\hline Parameters & Good outcome $(\mathrm{n}=127)$ & Poor outcome $(\mathrm{n}=23)$ & p-value* \\
\hline Maternal age $(\mathrm{y})$ & $24.85 \pm 3.41$ & $25.22 \pm 3.64$ & 0.65 \\
Birth weight $(\mathrm{kg})$ & $2.52 \pm 0.65$ & $2.63 \pm 0.54$ & 0.42 \\
HOL & $108.010 \pm 57.53$ & $122.52 \pm 64.28$ & 0.32 \\
Hb $(\mathrm{gm} / \mathrm{dl})$ & $14.83 \pm 2.28$ & $13.94 \pm 2.17$ & 0.08 \\
TLC $(\mathrm{count} / \mathrm{mm} 3)$ & $16943.39 \pm 7974.98$ & $17744.34 \pm 10116.36$ \\
TSB $(\mathrm{mg} / \mathrm{dl})$ & $20.18 \pm 3.56$ & $30.23 \pm 4.22$ & 0.82 \\
Phototherapy duration $(\mathrm{h})$ & $44.87 \pm 15.95$ & $61.05 \pm 14.05$ & $<\mathbf{0 0}$ \\
\hline
\end{tabular}

*Student's t-test. HOL: Hours of life, Hb: Hemoglobin, TLC:Total leukocyte count, TSB:Total serum bilirubin

have G6PD deficiency. In our study we could not find any cause of neonatal hyperbilirubinemia in $17.3 \%$ of babies. Similarly, causes of hyperbilirubinemia were unidentified in one-third of the patients in a study in India [1]. The most likely causes for this group with yet unknown etiology could be breastfeeding jaundice, breast milk jaundice or due to genetic variability $[7,9]$. Breastfeeding jaundice developed in 10 to $15 \%$ of exclusively breastfed infants during the first week of life [9]. Inadequate feeding may add to dehydration which may significantly increase serum bilirubin levels. A study revealed that inadequate breastfeeding may contribute up to $50 \%$ of pathological jaundice [2]. Several studies have revealed that bilirubin, in inadequately breastfed babies, is elevated like an increase in serum bilirubin seen with partial starvation in adults $[9,10]$.

The average time for presentation in our study was $110.2 \pm 58.6 \mathrm{~h}$ which also falls within the time of appearance of breastfeeding jaundice. Our babies' average time for the presentation was a bit longer than 60 hours reported in another study [7]. This may be due to the transportation constraints and hilly geographic location in our country. The mean total bilirubin level at presentation was $21.7 \mathrm{mg} / \mathrm{dl}$ in our patients. Studies have reported serum bilirubin before starting photo- therapy in the range of 16 to $22 \mathrm{mg} / \mathrm{dl}$ [7-10]. Our newborns had bilirubin level on the higher side which may be because of the delayed presentation.

In our study, $72 \%$ of the babies required only phototherapy. Twenty-eight percent babies who had total bilirubin levels at or above the exchange range at the time of presentation received both exchange transfusion and phototherapy [4]. Similar proportion of babies requiring different modalities of management as ours has been reported earlier [7]. In contrast, other studies have shown that exchange transfusion was required by fewer babies than ours [10-14]. We had higher rates of exchange transfusion perhaps due to delayed presentation and high value of total serum bilirubin (> $25 \mathrm{mg} /$ dl) at presentation. The duration of phototherapy in our babies was 47 hours. The duration of phototherapy has been variably reported in the range of 24 to 50 hours [7, 12-15].

More than four-fifths of our babies had good outcome without any residual neurological deficit at discharge and around $15 \%$ were diagnosed as acute bilirubin encephalopathy at discharge. Many investigators have followed up the newborns up to 1 to 3 months and found that the majority had no neurological impairments $[7,9,11,15]$. In our study, nearly $19 \%$ of the ba- 
bies had bilirubin level more than $25 \mathrm{mg} / \mathrm{dl}$ at presentation which might be the main reason accounting for the need of exchange transfusion and higher rates of acute bilirubin encephalopathy.

In our study, a high bilirubin at presentation, longer duration of phototherapy, ABO setting, hemolysis, and out born babies developed poor outcome. Similarly, the most common risk factor for significant hyperbilirubinemia in Pakistani study was home delivery (60\%), followed by prematurity, low birth weight (55\%), sepsis (52\%), and hemolysis (30\%) [16]. In a Canadian study the most common risk factor was $\mathrm{ABO}$ incompatibility in $52 \%$, followed by G6PD deficiency in $21 \%$, other antibody incompatibilities in $12 \%$, hereditary spherocytosis in $7 \%$, urinary tract infection in $2 \%$, and sepsis, pyruvate kinase deficiency, hypothyroidism, or unstable hemoglobin comprising of about $4 \%$ [17].

Approximately $15 \%$ of our babies with hyperbilirubinemia had an acute bilirubin encephalopathy. Similarly, about $14 \%$ of the neonates with severe hyperbilirubinemia had a neurological deficit at discharge in a Canadian study [17]. In a Nigerian study $9.7 \%$ of the overall subjects developed kernicterus [18]. In a study of Bangladesh, about $5 \%$ of the neonates had a bad neurological outcome including $2 \%$ neonatal deaths [19]. In Kanti children hospital, the mortality rate was about $6 \%$, which is way higher than ours and that reported in the literature [20]. Our findings may not reflect the national figure of neonatal hyperbilirubinemia and its outcome as this study was conducted in the tertiary care center of eastern Nepal where most of the babies with pathological hyperbilirubinemia are referred from other hospitals for exchange transfusion as it is the only place where exchange transfusion is performed till this study was concluded.
The neonates who had poor outcome had neurological deficit at discharge. Those babies were mostly out born/ home delivered and had significant hyperbilirubinemia $(20 \mathrm{mg} / \mathrm{dl})$ at presentation. They had presented with features of acute bilirubin encephalopathy with increased tone and decreased activity and most had hung up Moro's at admission. Most of the babies with poor outcome had ABO settings. Those babies who had peripheral smear suggestive of hemolysis had significant hyperbilirubinemia and almost all of them received exchange therapy and IV Immunoglobulin in addition to phototherapy and the duration of phototherapy was also longer in the babies with poor neurological outcome than those who had good outcome.

This study mainly reflects the outcome in eastern part of Nepal which may not imply to other parts of the country. If more similar studies are conducted at other centres in different parts of Nepal, the results may be generalized.

\section{CONCLUSION}

Tn this study, about $15 \%$ of the babies with hyperbili1 rubinemia had acute bilirubin encephalopathy at discharge suggestive of poor outcome. Babies with high bilirubin at presentation, longer duration of phototherapy, ABO settings, hemolysis, and out born status developed poor outcome. With still a high rates of invasive exchange transfusion accounting $32 \%$ at our centre, we recommend that proper information regarding neonatal jaundice should be provided to all mothers before discharge so that they may report back timely. This may help decrease the incidence of acute bilirubin encephalopathy in the newborns.
References

I. Shetty A, Kumar BS. A study of neonatal hyperbilirubinemia in a tertiary care hospital. Int J Med Sci Public Health. 2014;3: 1289-92. DOI: I0.5455/ijmsph.20I4.010820I4|

2. Xavier R, Manoj VC, Cherian VJ. Breastfeeding jaundice: How big is the problem? Int J Contemp Pediatr. 2016;3:498-503. DOI: I0.18203/2349-329|.ijcp20160948

3. Mary LP, Martin CR, Cloherty JP. Neonatal hyperbilirubinemia. In: Cloherty JP, Eichenwald EC, Hansen AR, Stark AR, editors. Manual of Neonatal Care. 7th ed. Philadelphia PA: Lipincott Williams and Wilkins; 20I2. p. 306-I4.

4. Provisional Committee for Quality Improvement and Subcommittee on Hyperbilirubinemia. Practice parameter: management of hyperbilirubinemia in the healthy term newborn. American Academy of Pediatrics. Pediatrics. 1994;94(4 Pt I):558-65. Erratum in: Pediatrics 1995;95(3):458-6I. PMID: 775569I.

5. Dangerfield Wg, Finlayson R. Estimation of bilirubin in serum. J
Clin Pathol. 1953;6(3): I73-7.

6. Yerushalmy J.The classification of newborn infants by birth weight and gestational age.J Pediatr. 1967;7I(2): 164-72.

7. Bedi N, Kumar CM, Singh S. A study of neonatal hyperbilirubinemia from a tertiary care hospital in Northern India. Indian J Child Health. 20I8;5(I2):7|7-9. DOI: I0.32677/IJCH.20I8.v05.iI 2.003

8. Davutoglu M, Garipardiç M, Guler E, Karabiber H, Erhan D. The etiology of severe neonatal hyperbilirubinemia and complications of exchange transfusion. Turk J Pediatr. 2010;52(2):I63-6. DOI: I0.3109/14767058.2014.960832

9. Demirkol M, Bohles H. Breast milk taurine and its possible influence on the development of breast milk induced jaundice of the neonate - A hypothesis. In: Hixtable R, Michalk DV, editors. Taurine in Health and Disease. New York: Plenum; 1994. p. 405- I0. DOI: I0. I007/978-I-4899-I47|-2_42

10. Gartner U, Goeser T, Wolkoff AW. Effect of fasting on the uptake 
of bilirubin and sulfobromophthalein by the isolated perfused rat liver. Gastroenterology. 1997; I 33(5): I707-13. DOI: 10.1053/ gast. 1997.v I 3.pm9352876.

II. Bandyopadhyay A, Maiti R. Fluid supplementation in term neonates with severe hyperbilirubinemia: A randomized controlled trial study. Int J Contemp Pediatr. 2017;4:853-7. DOI: 10.18203/2349. 329I.ijcp2017I597

12. Goyal P, Mehta A, Kaur J, Jain S, Guglani V, Chawla D. Fluid supplementation in management of neonatal hyperbilirubinemia: a randomized controlled trial. J Matern Fetal Neonatal Med. 20I8;3I(20):2678-84. DOI: I0.1080/I4767058.20I7.I35I535.

13. Yang WC, Zhao LL, Li YC, Chen CH, Chang YJ, Fu YC, et al. Bodyweight loss in predicting neonatal hyperbilirubinemia 72 hours after birth in term newborn infants. BMC Pediatr. 2013;13:145. DOI: 10.1 I86/I47|-243I-13-145

14. American Academy of Pediatrics Subcommittee on Hyperbilirubinemia. Management of hyperbilirubinemia in the newborn infant 35 or more weeks of gestation. Pediatrics. 2004; I I (I):297316. DOI: 10.1542/peds.II4.I.297. Erratum in: Pediatrics. 2004; I I4(4): II 38.

15. Bhatia J, Mundy CA. Immunoglobulin transfusion in haemolytic disease of the newborn: Place in therapy. Int J Clin Transfus Med. 20I5;3:4I-5. DOI: I0.2I47/IJCTM.S400I9.

16. Ahmad M, Rehman A, Adnan M, Surani MK. Acute bilirubin encephalopathy and its associated risk factors in a tertiary care hospital, Pakistan. Pak J Med Sci. 2020;36(6):I I89-92. DOI: I0.12669/ pjms.36.6.2222.
17. Sgro M, Campbell D, Shah V. Incidence and causes of severe neonatal hyperbilirubinemia in Canada. CMAJ. 2006; 175(6):587-90. DOI: 10.1503/cmaj.060328

18. Onyearugha CN, Onyire BN, Ugboma HAA. Neonatal jaundice: Prevalence and associated factors as seen in Federal Medical Centre Abakaliki, Southeast Nigeria. J Clin Med Res. 20I I;3(3):40-5. DOI: 10.5897/JCMR.9000034

19. Rasul CH, Hasan MA, Yasmin F. Outcome of neonatal hyperbilirubinemia in a tertiary care hospital in bangladesh. Malays J Med Sci. 20 10; 17(2):40-4. PMID: 22।35536; PMCID: PMC32।6I55.

20. Nepal D, Banstola D, Khakal A, Mishra U, Maheseth C. Clinico-laboratory profile and immediate outcomes of hyperbilirubinemic babies admitted in Kanti Children Hospital. Journal of Nepal Paediatric Society. 20 I0;30(I):3 I-6. DOI: I0.3 I26/jnps.v30il.2457 